This item was submitted to Loughborough's Research Repository by the author.

Items in Figshare are protected by copyright, with all rights reserved, unless otherwise indicated.

\title{
Numerical study of crack initiation and growth in human cortical bone: Effect of micro-morphology
}

PLEASE CITE THE PUBLISHED VERSION

https://doi.org/10.1016/j.engfracmech.2020.107051

\section{PUBLISHER}

Elsevier BV

VERSION

AM (Accepted Manuscript)

\section{PUBLISHER STATEMENT}

This paper was accepted for publication in the journal Engineering Fracture Mechanics and the definitive published version is available at https://doi.org/10.1016/j.engfracmech.2020.107051.

LICENCE

CC BY-NC-ND 4.0

\section{REPOSITORY RECORD}

Wang, Mayao, Simin Li, Annika vom Scheidt, Mahan Qwamizadeh, Björn Busse, and Vadim Silberschmidt. 2020. "Numerical Study of Crack Initiation and Growth in Human Cortical Bone: Effect of Micro-morphology". Loughborough University. https://hdl.handle.net/2134/12196056.v1. 


\title{
Numerical study of crack initiation and growth in human cortical bone: Effect of micro-morphology
}

\author{
Mayao Wang ${ }^{\mathrm{a}, 1}$, Simin $\mathrm{Li}^{\mathrm{a}, 1}$, Annika vom Scheidt ${ }^{\mathrm{b}}$, Mahan Qwamizadeh ${ }^{\mathrm{b}}$, \\ Björn Busse ${ }^{\mathrm{b}}$, Vadim V. Silberschmidt ${ }^{\mathrm{a}, *}$ \\ ${ }^{\mathrm{a}}$ Loughborough University, Leicestershire LE11 3TU, UK \\ ${ }^{\mathrm{b}}$ University Medical Center Hamburg-Eppendorf, Lottestr. 55A, 22529 Hamburg, Germany
}

\begin{abstract}
A B S T R A C T
In this study, crack initiation and growth in four different groups of human cortical bones, i.e., young, aged, diseased (osteoporosis) and treated are investigated numerically with a zerothickness Cohesive Element Method, employing statistical realisations of randomly distributed microstructural constituents. The obtained simulation results demonstrated distinct crack paths in bones with varying microstructures, based on analysis of initiation, propagation and branching of multiple cracks, with supporting fracture toughening mechanisms. It is shown that superior mechanical properties and fracture resistance in the young and treated groups originated from both the qualitative and quantitative features of microstructural constituents.
\end{abstract}

\author{
Keywords: \\ Cortical bone \\ Micro-morphology \\ Crack propagation \\ Cohesive element \\ Multiple cracks
}

\section{Introduction}

Ageing and degenerative bone diseases such as osteoporosis increase the risk of bone fracture, detrimentally affecting the normal day-to-day life. The demographic shifts in population and the ageing society result in an increasing number of osteoporosis- and ageing-related fractures causing significant public-health problems. In the UK alone, over 300,000 fragility fractures occur each year and the associated treatment cost was estimated at $2 \%$ of the total healthcare budget, around $£ 3$ bn per year [1]. In general, treatment of osteoporosis is associated with the use of standard medical diagnosis including dual-energy X-ray absorptiometry to measure the bone mineral density and subsequent pharmacologic therapies such as the use of bisphosphonates, which restrain the excessive loss of bone mineralisation. The treatment process is also accompanied by various changes in morphology of the microstructural constituents (here termed microconstituents) in cortical bone [2]. Previous studies showed that the effect of aging and bone diseases could result in significant decreases in bone fracture toughness. A report [3] suggested that aging alone can cause a five-fold decrease in crack-growth toughness, while a vitamin D-deficient tissue can result in 20-30\% lower toughness compared with a health counterpart. There is mounting evidence that the quality of bone, e.g. bone mineral density as well as the underlying micro-morphology and distribution of its microconstituents, contributes to significant variations of the mechanical competence and fracture resistance of bone $[2,4,5]$. However, studies thus far have not reached a consensus as to what extent each of these contributing factors affect the tissue integrity and fracture resistance. Due to the heterogeneous and hierarchal nature of the bone tissue spanning multiple length scales, it is currently not possible to separate these physical factors in experiments. Further, up to now, few numerical models exist,

\footnotetext{
* Corresponding author at: Wolfson School of Mechanical, Electrical and Manufacturing Engineering, Loughborough University, Ashby Road, Leicestershire, LE11 3TU, UK Leicestershire LE11 3TU, UK.

E-mail address: V.Silberschmidt@lboro.ac.uk (V.V. Silberschmidt).

${ }^{1}$ Equal contribution.
} 
which are capable to evaluate the morphological factors as well as the distribution of the microconstituents, separately from the bone's mechanical performance. Single-constituent models provide simple but detailed understanding of local stress-strain states and crack propagation directions. However, they do not accurately represent the complex collaboration of the multiple distributed constituents.

At microscale, a cortical bone tissue could be treated as a natural composite material with four main existing constituents, namely, osteons, Haversian canals, cement lines and interstitial matrix. Osteons are usually found in cross-sections of cortical bone, with a diameter of 100-250 $\mu \mathrm{m}$ [6]. At their centre, a Haversian canal, which is approximately 50-90 $\mu \mathrm{m}$ in diameter [7], contains blood vessels and nerve fibres. Together, they form the Haversian system, which undergoes continuous morphological change throughout life, known as the remodelling process, or as a result of ageing and bone diseases [8]. The remodelling process generates newly formed secondary osteons within the interstitial matrix, separated with a thin interface called cement line, typically, 2-5 $\mu \mathrm{m}$ in thickness [9]. In several studies $[10,11]$, ageing and bone diseases were considered to have a negative impact on the bone remodelling process. Serious changes in the morphological structure of bone and its constituents (e.g. increasing the porosity and decreasing the mineral content and osteonal area) are associated with ageing $[12,13]$. Moreover, diameters of osteons and Haversian canals were found to decrease or increase, respectively, with ageing and osteoporotic conditions [2]. On the other hand, heterogeneous distributions of microstructural constituents were said to affect not only the material properties of bone tissue [12] but also the local distributions of stresses and strains as well as crack propagation in case of fracture [14]. Still, it remains challenging to investigate experimentally the mechanism of crack propagation in cortical bone, originating from different patient groups. In this paper, a novel computational method is adopted to evaluate the crack propagation process, accounting for specific bone microstructures.

Simulations of crack initiation and propagation in cortical bone were performed previously using either the Cohesive Zone Element (CZE) Method [15-19] or the Extended Finite Element Method (X-FEM) [20-23]. Both CZE and X-FEM approaches have their advantages in simulating crack initiation and propagation, i.e. lower computational cost compared to other finite-element techniques with the same level of accuracy. However, they also have limitations: the necessity for a predefined crack path in the case of the CZE or the lack of crack multiplication and bifurcation in X-FEM based models. Until now, computational mechanics has efficiently helped to provide various important insights of the fracture behaviour of cortical bone tissue. Single-osteon models with idealised geometry were employed to understand some fundamental questions, for instance, possible mechanisms affecting crack propagation and deflection [19] and the effect of different fracture-mechanics approaches on crack initiation and propagation using X-FEM [23]. Early work by Yang et al. [15] used a homogenized CZE model to elucidate the necessity of a nonlinear fracture model to account for a complex fracture process of cortical bone. Similar approaches were used to investigate the effect of hydration on crack propagation behaviour of cortical bone [17] and the influence of ageing and strain rate on bone fracture toughness [15,23]. Multiscale and microstructure-based models were developed to simulate growth of multiple cracks in cortical bone under tension [20] and the effects of microstructural constituents and their mechanical properties on crack paths [17,20,21,24].

The aim of this study is to develop a novel zero-thickness Cohesive Element Method [14,17,23,25,26] combined with a cortical-bone model with a randomly distributed microstructure to investigate the effects of micro-morphology on mechanical properties, crack initiation and growth in human cortical bone for four patient groups: young, aged, diseased (osteoporosis) and treated with bisphosphonate. The micro-morphology parameters of cortical bone were obtained based on the data for the respective patient groups.

\section{Materials and measurement}

Representative images of samples taken from four groups of cortical-bone specimens (young group: $32 \pm 8$ years; aged group: $79 \pm 9$ years; diseased (osteoporosis) group: $81 \pm 7$ years; and drug-treated (bisphosphonate) group: $81 \pm 9$ years), acquired from the proximal femoral diaphysis of 35 female donors (aged from 24-88) were analysed (Fig. 1) [2]. Over 100 osteonal systems were examined in each group to provide representative group-specific morphological parameters.

First, areal fractions of the three microconstituents - osteons, porosity and interstitial matrix - were assessed with the following steps:

1. Outline and perimeter of the bone specimens were identified in order to calculate areal fraction of the cortical tissue accurately.

2. Existing microcracks were distinguished from other microconstituents using a colour filter and were excluded from subsequent analysis of areal fraction.

3. When the boundary of the osteon was not clear, Image Pro software was used to increase the contrast of images; automatic feature recognition and manual operations were used to present each microconstituent with different colours: red, green and blue, representing porosity, osteonal area and the interstitial matrix, respectively.

4. Areal fractions of each microconstituent were calculated by counting the number of pixels of the respective colours.

Then, the distributions of the parameters of the osteonal system, including osteons (each defined as ellipse with two axes and an angle of inclination - measured anti-clockwise from the positive x-axis of a cartesian coordinate) and concentric Haversian canals (assumed to have a circular shape) (Fig. 2) were fitted against morphological data using a best-fit function. Finally, a Matlab programme was developed to generate models with randomly distributed microconstituents of cortical bone based on parameters obtained for each patient group (Fig. 1). The iterative programme continued until the resulting microstructured models in each group satisfied all the statistical distributions of the osteonal parameters as well as the areal fractions of the microconstituents of the respective group. A comparison of the areal fractions of microconstituents between each simulated model and the experimental measurement for each group are given in Table 1 . 


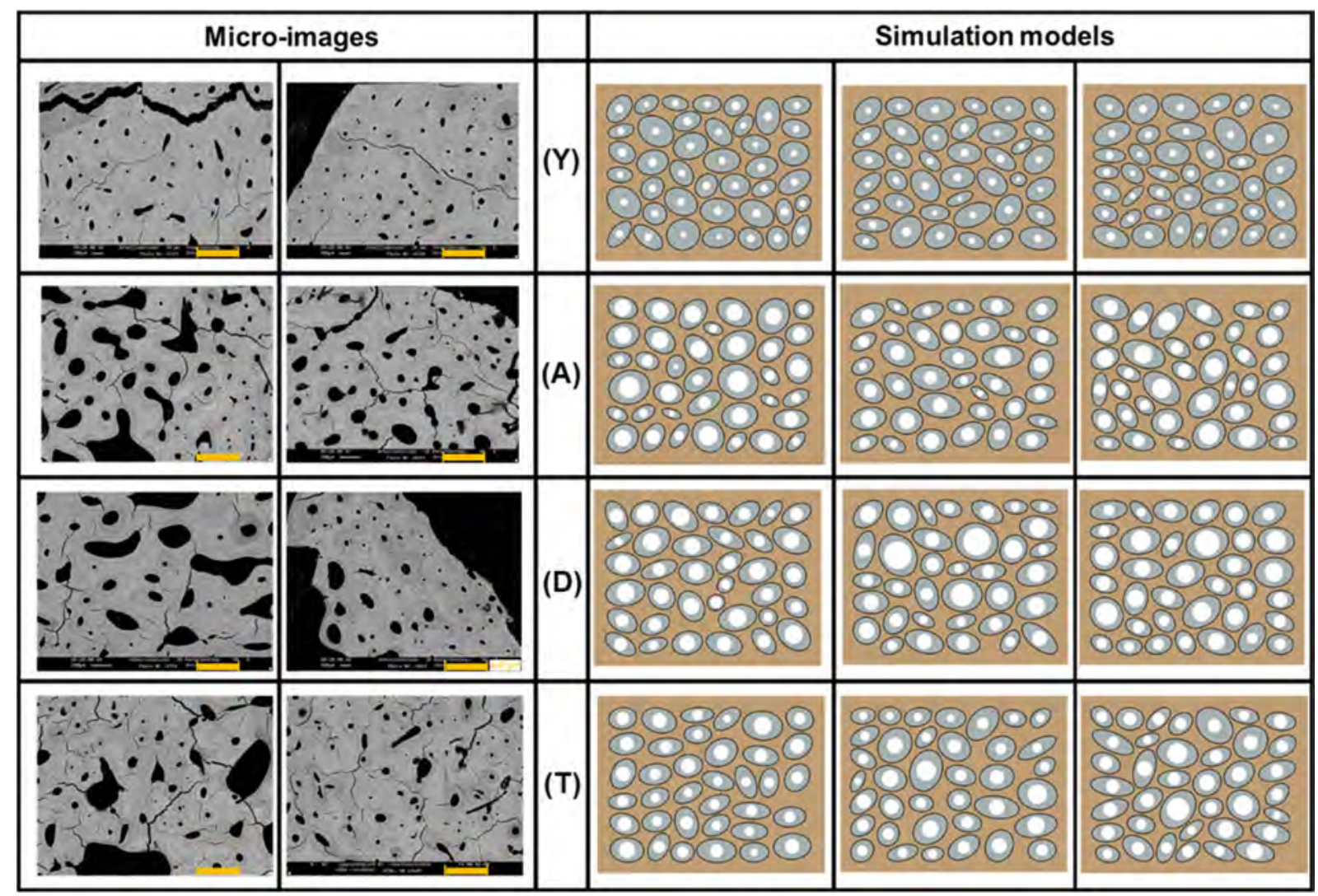

Fig. 1. Experimental backscattered electron microscopic images ( $400 \mu \mathrm{m}$ scale bar in brown) and three statistical realisations of generated models with randomly distributed microstructural elements of human cortical bones in transverse section of four groups ( $\mathrm{Y}-$ young, A - aged, T - treated, D - diseased).

\section{Model development}

\subsection{Introduction of cohesive elements}

The developed numerical models employed standard continuum finite elements. Between them, discontinued surfaces representing cracks or material interfaces were defined by zero-thickness cohesive-zone elements. A Matlab program was developed to insert these CZEs into the existing Abaqus model, using the following protocol [15-17].

(1) Define edges of each element in the Abaqus input file, which would be used to insert cohesive elements (Fig. 3a-1).

(2) Duplicate the nodes, sharing the same edge and coordinates, and assign these new nodes to one of two standard triangular finite elements to have a total of six nodes for the adjacent two elements, instead of the previous four nodes (Fig. 3a-2).

(3) Generate the zero-thickness cohesive element (COH2D4) based on two old and two new nodes (Fig. 3a-3).

Material softening at the vicinity of the crack tip was modelled with a traction-separation relationship implemented in the cohesive elements (Fig. 3b). The zero-thickness cohesive element had a linear elastic behaviour; upon reaching the critical point (defined by the $\sigma_{c}$ and $\delta_{c}$ ), a crack was assumed to initiate at $\delta_{c}$, and the reaction force of the cohesive element reduced as a result of damage softening until reaching the failure point at $\delta_{u}$. This was governed by the strain energy release rate $\left(G_{c}\right)$ of respective microconstituents. A quadratic, nominal-strain-based damage initiation criterion (QUADECRT) and an energy-based linear damage evolution criterion (SDEG) were applied in the model.

\subsection{Model specification}

Prior to the current study, a mesh-sensitivity test that employed four mesh sizes $(0.01 \mathrm{~mm}, 0.015 \mathrm{~mm}, 0.02 \mathrm{~mm}$ and $0.025 \mathrm{~mm})$ was conducted and convergence was achieved with an average mesh size of $0.02 \mathrm{~mm}$. Mechanical properties of microstructural constituents of human bone, such as osteons, interstitial area and interface between the cement line and interstitial bone (CL-IB interface) were adopted based on previous research [23,25] (Table 2). It is well documented that disease and aging affect bone 


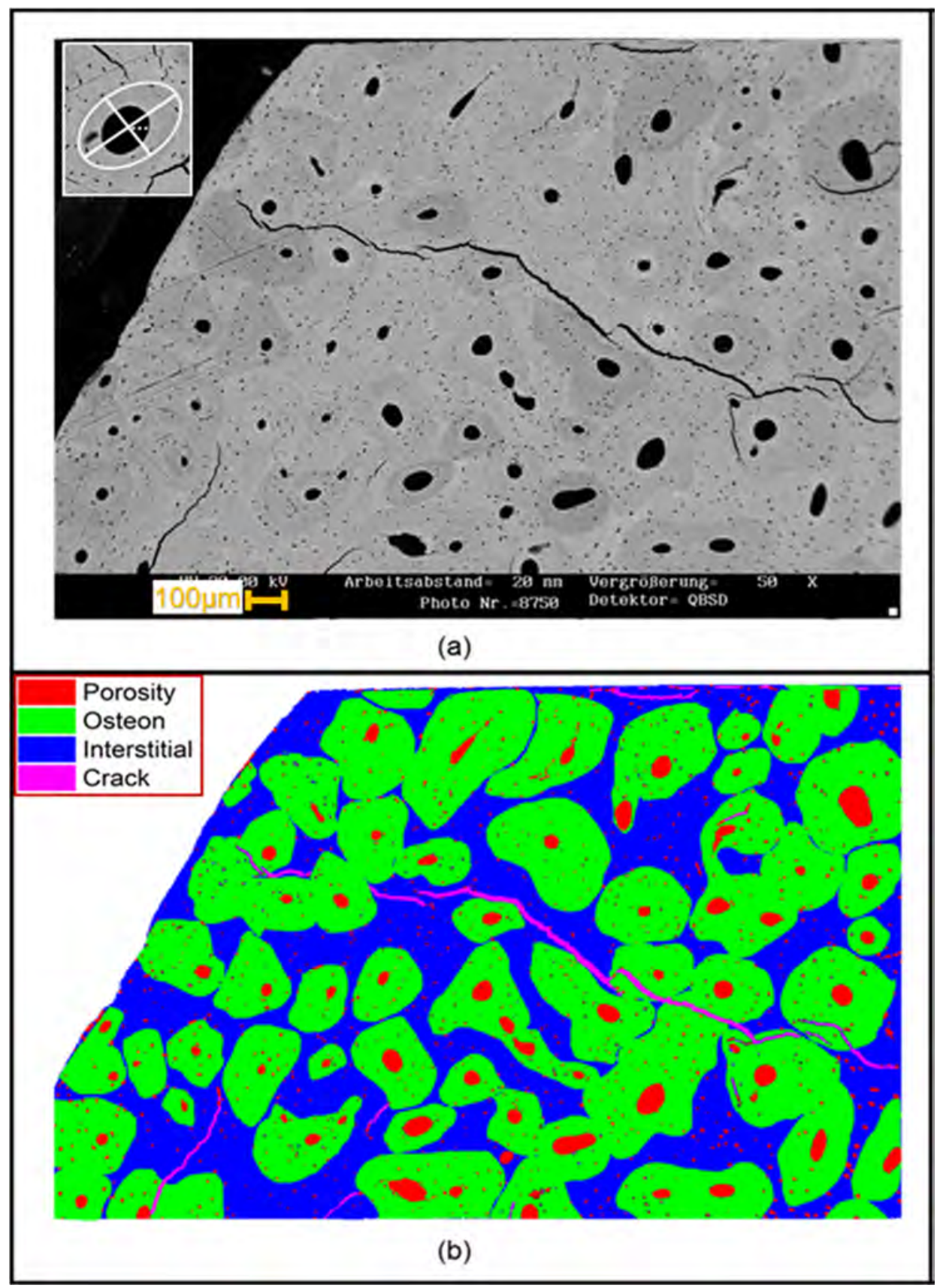

Fig. 2. Analysis process of backscattered electron microscopic images: (a) original image with parametrised representation of exemplary osteon as ellipse (insert); (b) analysed image: osteons (green), interstitial area (blue), porosity area (red) and crack area (purple).

turnover (resorption and formation) [27], which, in turn, leads to variations on the elastic modulus of microconstituents [25]. However, in the current study, the focus was on the effect of micromorphology of the constituents; hence, a single set of properties was assumed throughout the study instead of employing varying values based on aging, disease and other co-contributing factors (this will be a subject of the subsequent study). The elastic moduli of osteons and interstitial matrix were obtained from nanoindentation experiments [25]. It should be also acknowledged that the understanding of mechanical behaviour of cement lines remains an active - and somewhat controversial - area of research [28-30]. Therefore, a CL-IB interface region, instead of cement lines, as in previous studies [20,23,25], was modelled. The module of CL-IB interface was assumed to be $25 \%$ lower than that of the osteon, mimicking behaviour of a less stiff interlamellar region, with abundant loosely packed collagen fibrils and noncollagenous proteins were [31,32]. The failure of human cortical bone in transversal direction was assumed to occur at the maximum principal strain of $0.4 \%[33,34]$. The critical strain-energy release rate was calculated from the previous study [25]. 
Table 1

Areal fractions of microconstituents of four groups (each group had three simulated statistical realisations based on experimental data).

\begin{tabular}{|c|c|c|c|c|c|c|}
\hline & \multicolumn{2}{|c|}{ Porosity (\%) } & \multicolumn{2}{|c|}{ Osteons (\%) } & \multicolumn{2}{|c|}{ Interstitial area (\%) } \\
\hline & Model & Measurement & Model & Measurement & Model & Measurement \\
\hline \multirow[t]{3}{*}{ Young } & 5.96 & $5.96 \pm 0.66$ & 60.03 & $60.03 \pm 3.39$ & 34.01 & $34.01 \pm 2.74$ \\
\hline & 5.31 & & 56.61 & & 34.66 & \\
\hline & 5.94 & & 49.68 & & 44.38 & \\
\hline \multirow[t]{3}{*}{ Aged } & 18.10 & $18.10 \pm 5.46$ & 40.79 & $40.79 \pm 1.11$ & 41.11 & $41.11 \pm 4.53$ \\
\hline & 17.09 & & 41.15 & & 41.76 & \\
\hline & 13.81 & & 41.51 & & 44.68 & \\
\hline \multirow[t]{3}{*}{ Diseased } & 15.22 & $15.22 \pm 8.96$ & 45.38 & $45.38 \pm 1.11$ & 39.40 & $39.40 \pm 10.07$ \\
\hline & 20.21 & & 41.01 & & 38.78 & \\
\hline & 17.67 & & 45.93 & & 36.40 & \\
\hline \multirow[t]{3}{*}{ Treated } & 17.13 & $17.13 \pm 5.34$ & 46.68 & $46.68 \pm 0.92$ & 36.19 & $36.19 \pm 6.26$ \\
\hline & 13.98 & & 45.69 & & 40.33 & \\
\hline & 13.09 & & 46.46 & & 40.45 & \\
\hline
\end{tabular}

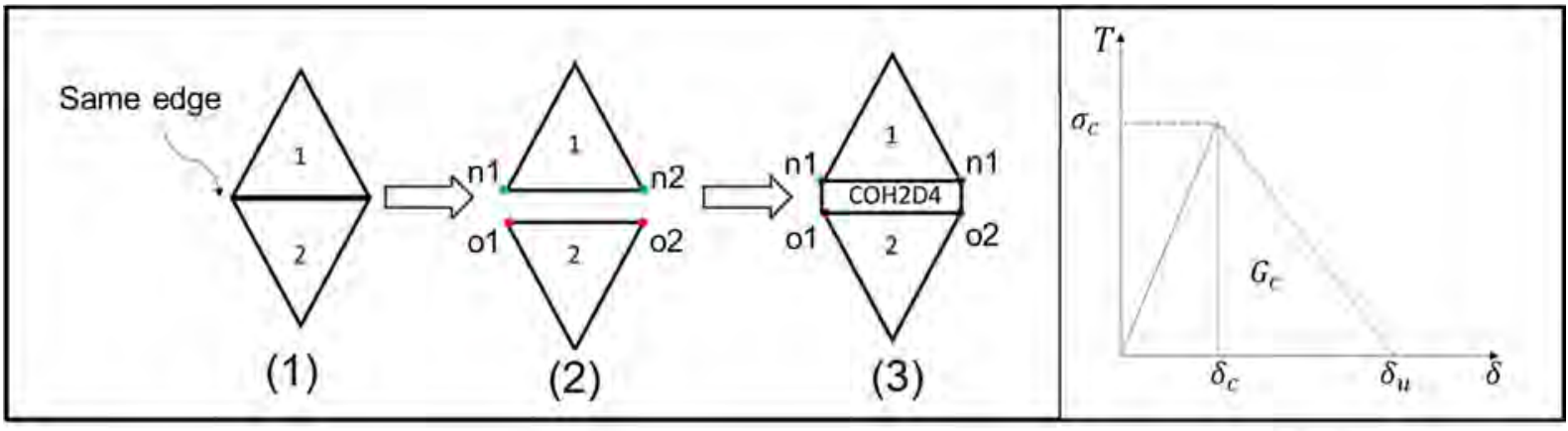

(a)

(b)

Fig. 3. (a) Process of inserting zero-thickness cohesive elements (o - old nodes; $n$ - new nodes); (b) traction-displacement relationship of cohesive zone model $\left(\sigma_{\mathrm{c}}, \delta_{\mathrm{u}}\right.$ and $\mathrm{G}_{\mathrm{c}}$ are critical stress, displacement at failure and critical energy release rate, respectively).

Table 2

Material properties of microstructural constituents of cortical-bone tissue [23,25].

\begin{tabular}{llll}
\hline Model & Elastic modulus (GPa) & Poisson's ratio & Critical strain-energy release rate (N/mm) \\
\hline Osteon & 13.50 & 0.33 & 0.120 \\
Interstitial matrix & 14.60 & 0.3 & 0.132 \\
CL-IB interface & 10.12 & 0.41 & 0.084 \\
\hline
\end{tabular}

A uniaxial tensile displacement of $0.04 \mathrm{~mm}$ was applied to the top edge of the model (Fig. 4) while the bottom edge was pinned at the centre allowing lateral translations of its other nodes. Three-node plane-strain triangle elements (CPE3) and four-node twodimensional cohesive elements were used for modelling the cortical bone and CL-IB interface, respectively. The model was running on a high-performance cluster (HPC) using Abaqus/explicit. A one-way non-parametric ANOVA (Kruskal-Wallis) test was performed to analyse the statistical significance of results obtained for the four studied groups.

A separate numerical study considering a case of hypermineralised cement lines was also performed; it is discussed in Appendix A.

\section{Results}

\subsection{Morphological variation}

The analysis of microscopic images confirmed that the morphological characteristics of cortical bone varied among the four groups (Fig. 5). The young (Y) group had the highest average osteonal area $(60.03 \% \pm 3.39 \%)$ and lowest porosity $(5.96 \% \pm 0.66 \%)$ of all the groups, followed by the treated $(\mathrm{T})$ (osteonal area: $46.68 \pm 0.92 \%$, porosity: $17.13 \pm 5.34 \%$ ), diseased (D) $(45.38 \pm 1.11 \%, 15.22 \pm 8.96 \%)$ and aged (A) $(40.79 \pm 1.11 \%, 18.10 \pm 5.46 \%)$ groups. Regarding the mean interstitial area, the order was in reverse: the highest value occurred in the aged group $(41.11 \% \pm 4.53 \%)$, while the lowest in the young group $(34.01 \% \pm 2.74 \%)$. Further analysis of the distributions of individual osteonal systems revealed that the young group had a significantly smaller Haversian radius $(p<0.05)$ characterised by its distribution peak at a lower Haversian radius value and narrower 


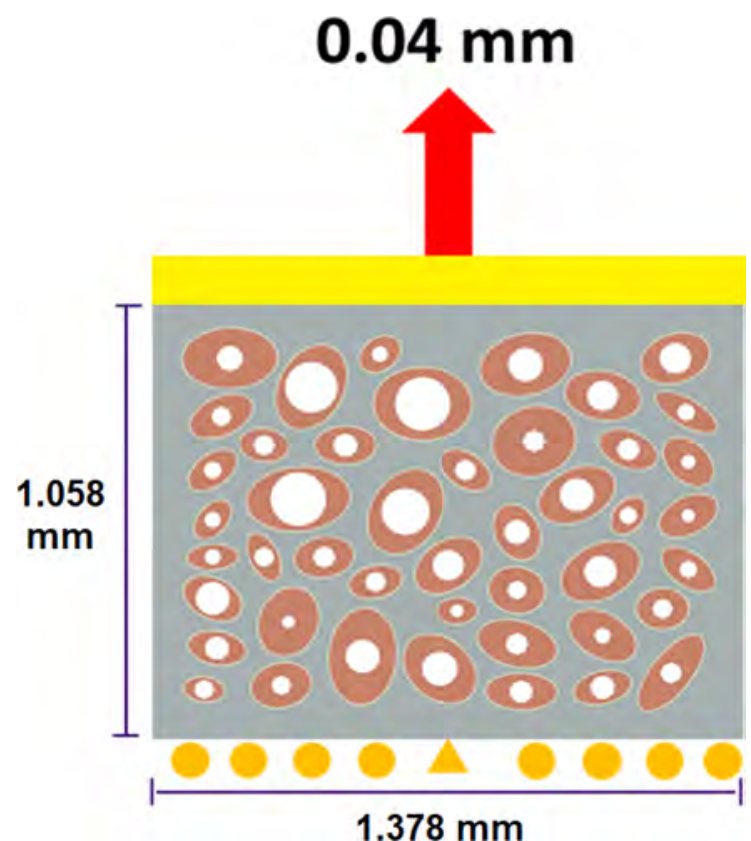

Fig. 4. Uniaxial-tension loading condition and model dimensions.

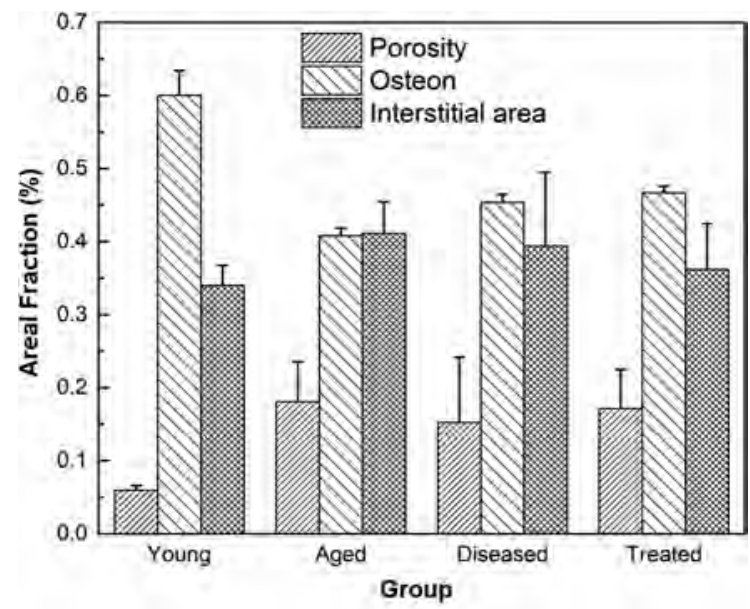

Fig. 5. Comparison of areal fractions of microstructural constituents of human cortical bone for four groups (In the image analysis, existing cracks were excluded from the total bone areal fraction; both haversian canals and lacunae contributed to the areal fraction of porosity; statistical analysis was not performed due to a limited data set).

spread (Fig. 6-a). In contrast, the young group had a significantly larger osteonal area $(p<0.05)$ with a wider spread compared with that of the aged group (Fig. 6-b). No significant difference was found in terms of the aspect ratio of osteons in all the groups. The statistical results for the bone micro-constituients indicate that the ageing process and diseases could influence the balance of the remodelling process, which in turn, cause the apparent changes in morphological parameters [35].

\subsection{Effect on mechanical properties}

The results obtained from numerical simulations for different statistical realisations of the cortical-bone model show that human cortical bone behaves as a brittle material when loaded in tension along its transversal direction, coinciding with the experimental observations [36]. The magnitudes of the effective elastic modulus, failure strain and ultimate tensile strength (UTS) averaged for the four groups are $10.56 \pm 1.19 \mathrm{GPa}, 0.367 \pm 0.019 \%$ and $32.12 \pm 5.34 \mathrm{MPa}$, respectively (Fig. 7), and in agreement with values from the literature $[27,28]$.

The effective modulus of the tissue, calculated for a region between the origin and the peak stress, was $12.36 \pm 0.25 \mathrm{GPa}$ for the young group and, thus, $23.6 \%$ higher than the average of the other three groups. In contrast, the diseased group had the lowest tissue 


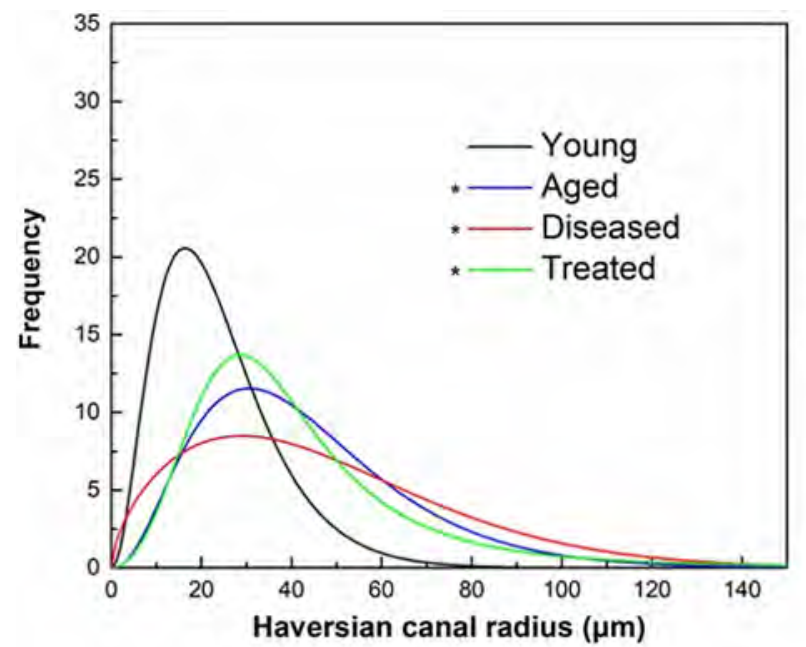

(a)

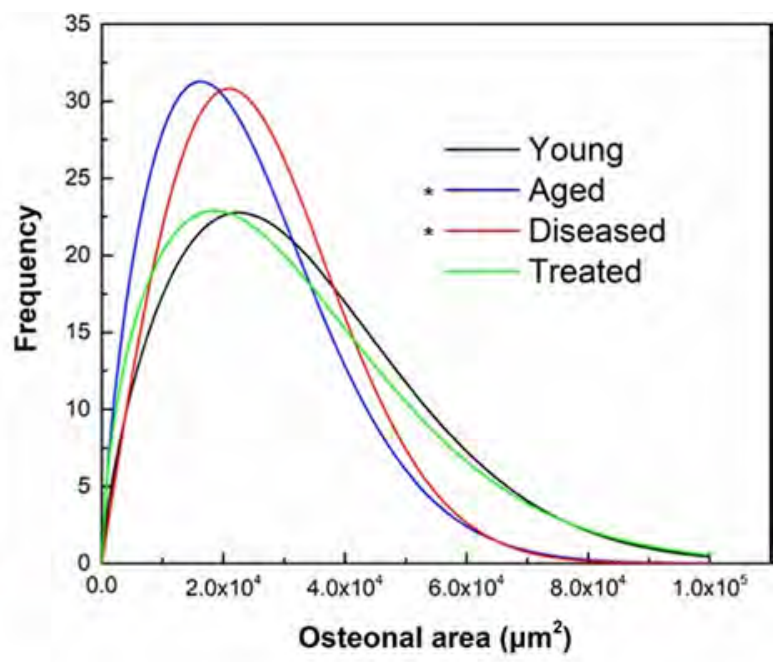

(b)

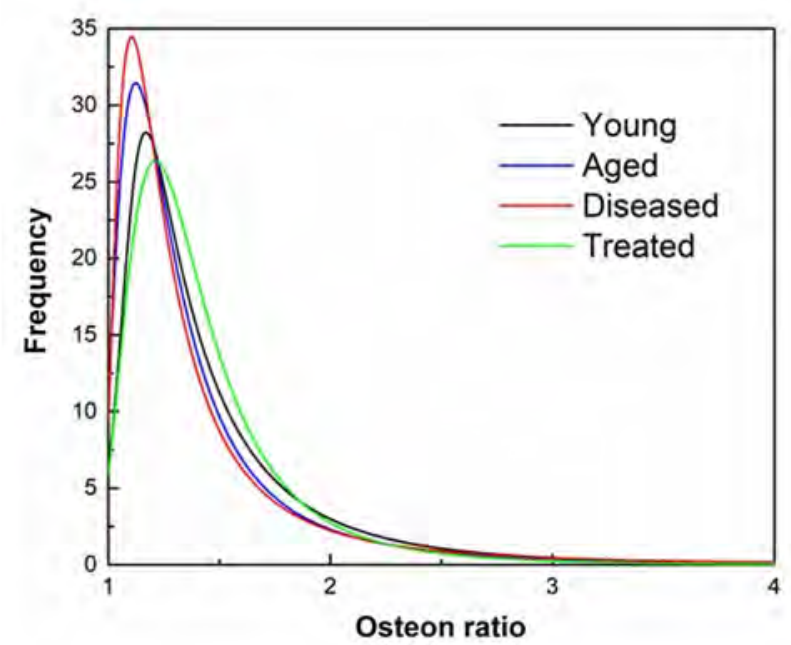

(c)

Fig. 6. Probability density distribution of Haversian canal radius (a), osteonal area (b) and ratio of long axis to short axis for osteons (c) in human cortical bones (* denotes that the group has a significant difference $(\mathrm{p}<0.05)$ with the young and treated group, respectively).

modulus $(9.44 \pm 0.28 \mathrm{GPa})$ of all the groups, which was $23.6 \%$ lower than that of the young group. On average, the treated group $(10.55 \pm 0.23 \mathrm{GPa}$ ) had a $10 \%$ higher elastic modulus compared with the diseased group; it was only slightly lower (by $7 \%$ ) than that of the aged group. Both the ultimate tensile strength and failure strain of human cortical bone for the four groups demonstrated a similar trend, with the young and diseased groups being the extremes and the treated group showing slightly higher values compared with the diseased group. Interestingly, variation of the failure strain among groups was relatively small (compared with the other two parameters), ranging between $0.34 \%$ and $0.39 \%$, i.e. a span of $12.8 \%$ for all the models.

The differences between mechanical properties of cortical bone of the four groups were further manifested by their diverging stress-strain behaviours, as seen in Fig. 8a. Stresses were calculated at tissue level as the force over the sample width (2D) and were plotted against tissue strains, defined as applied displacement over the original tissue length. To further understand the impact of varying porosity, the stress-strain curves were normalised with the areal fraction of the solid phases - osteons and interstitial matrix of each group as displayed in Fig. 8b. This normalization did not alter the relative order of values for the elastic properties (Young's modulus, ultimate strength and failure strain) of the groups, with the young group remaining the strongest.

Beyond the elastic range, mechanical behaviours of the groups diverged more prominently, partially due to the differences in crack initiation and propagation processes. To better illustrate the effect of damage on mechanical performance of the four groups, the stresses were normalised with respective ultimate tensile strengths and plotted against concurrent strain values for a post-critical behaviour in Fig. 9. The curves shown start at the ultimate tensile stress and end when the first cohesive element fails, leading to unstable crack propagation and rapid material degradation. Both the diseased and aged groups show damage initiation at low strains 


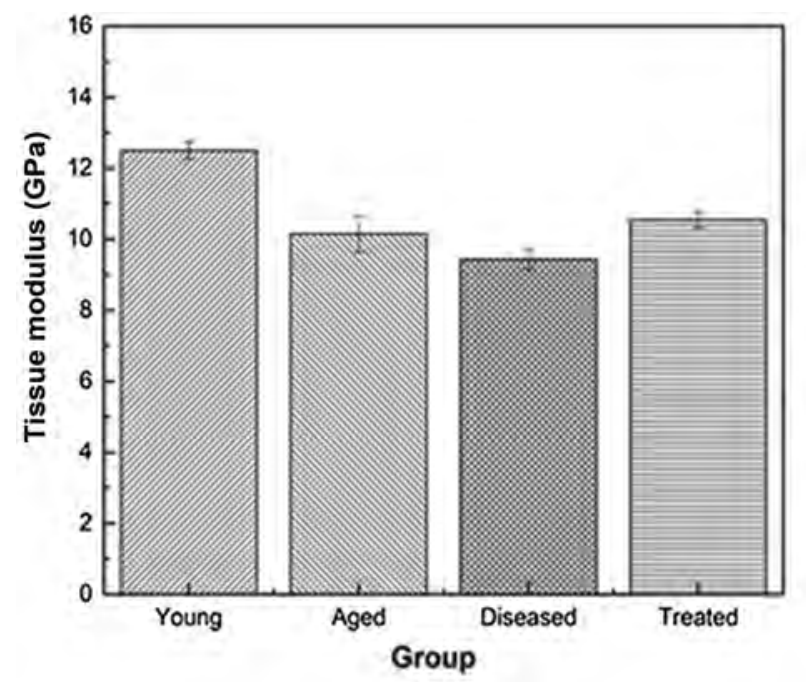

(a)

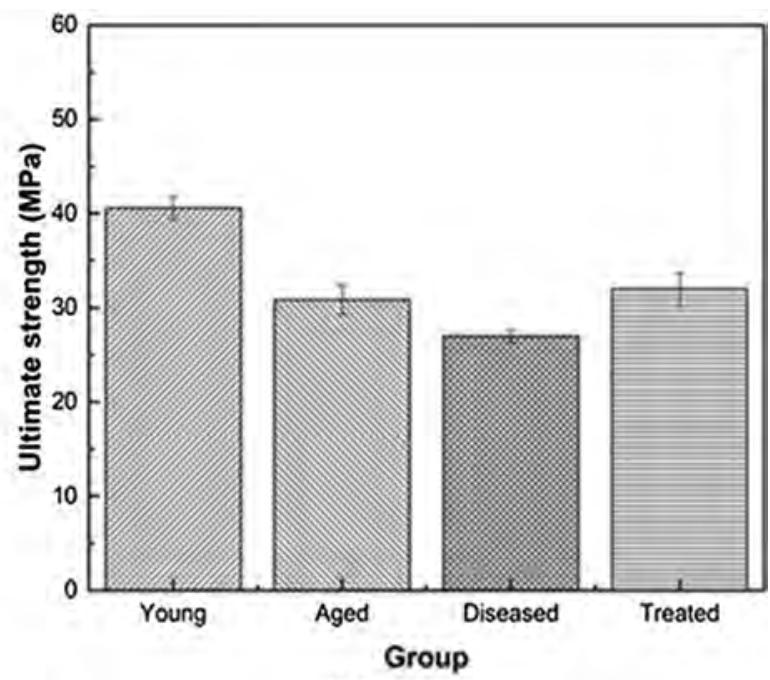

(b)

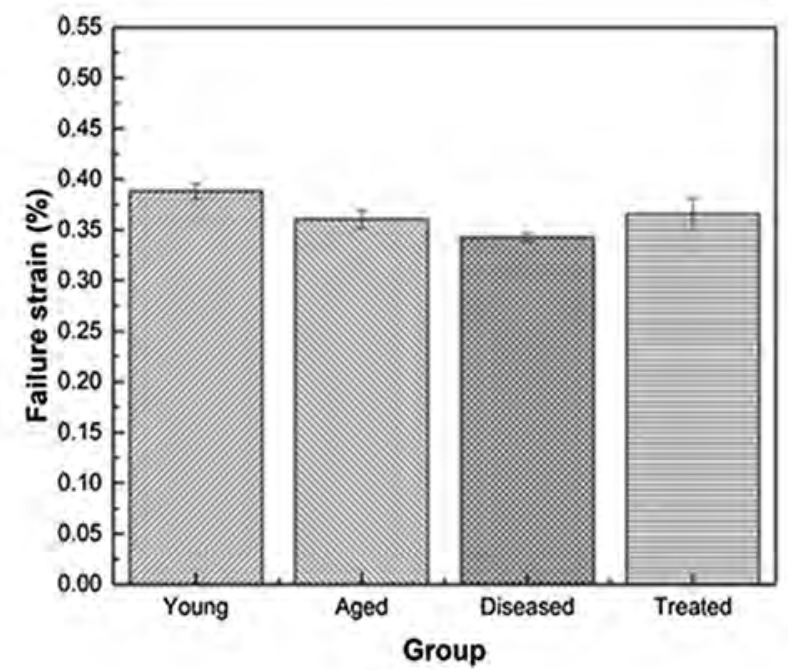

(c)

Fig. 7. Tissue modulus (a), ultimate strength (b) and failure strain (c) for four groups.

$(0.343 \pm 0.004 \%$ and $0.365 \pm 0.08 \%$, respectively) compared with the other two groups. However, the damage evolution process of the aged group proceeded to higher strains than in the diseased group, reaching a failure strain of $0.423 \pm 0.018 \%$ compared with $0.393 \% \pm 0.023 \%$. The treated groups, on the other hand, had a delayed damage initiation process, at $0.373 \pm 0.015 \%$, and had the same failure strain as the aged group. The young group showed the latest damage initiation and the longest damage softening span, coinciding with the highest load-bearing capacity of all the groups at any given strain.

\subsection{Effect on crack initiation and propagation}

Crack evaluation in each microstructured cortical bone model was further analysed to understand the effect of micro-morphology on the characteristics of fracture propagation. The results for fully opened crack paths are summarised in Fig. 10.

In general, the initiation of cracks began predominantly at large Haversian canals and/or free edges, where the local strain energy was higher due to the adjacent Haversian canal. This phenomenon was especially prominent in the diseased group, with more crack paths initiating at Haversian canals observed at an early stage of the fracture process, mostly due to high porosity, large Haversian canals and smaller osteon diameter. The propagation of the cracks, however, was much more complex. Multiple cracks originating from both the free edges and large Haversian canals were evident, showing no specific pattern as a result of randomly distributed microconstituents and their varying morphologies. Propagation of the cracks revealed some intricate toughening mechanisms: kinks and deflection around microconstituents as well as crack arrest and bridging at the crack tip due to localised stress relaxation were apparent in all the groups. It was particularly noticeable that there was a strong presence of crack deflection at the interface between 


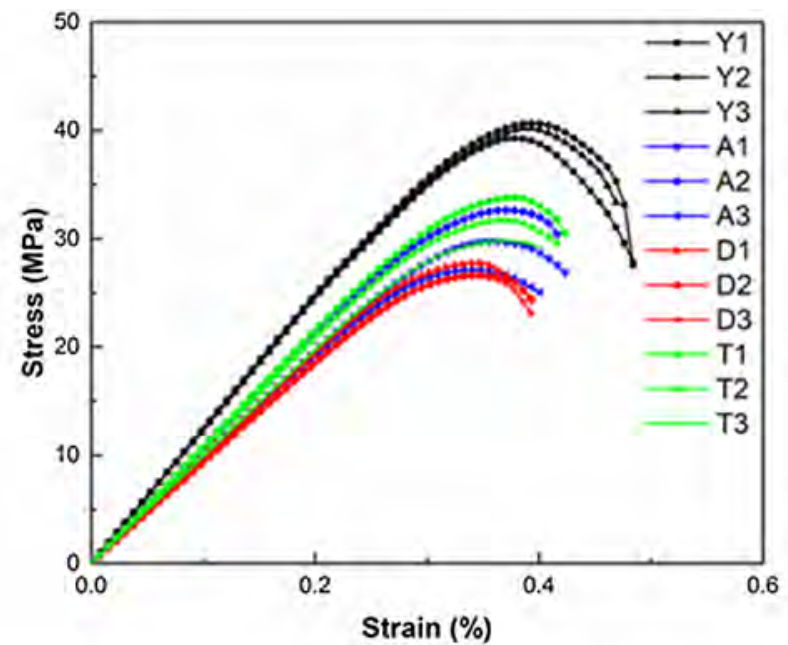

(a)

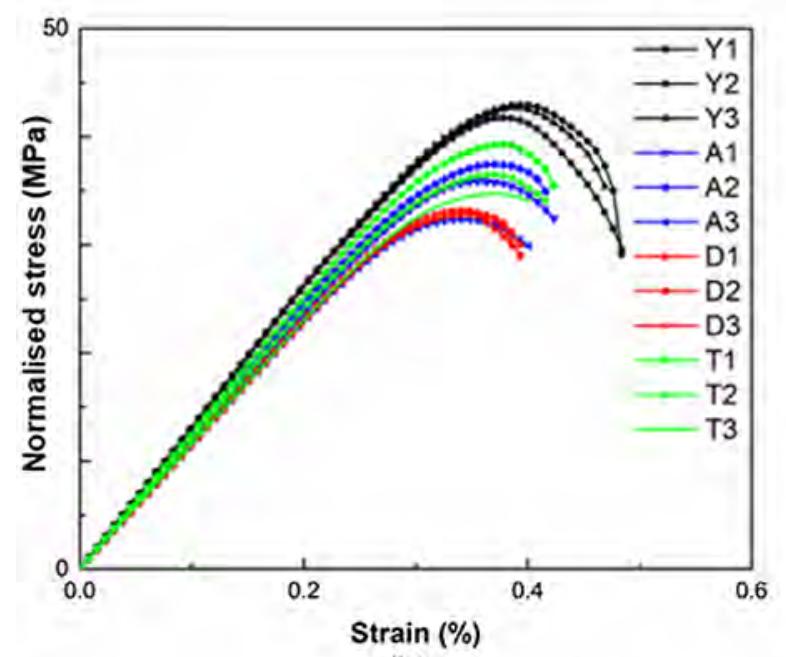

(b)

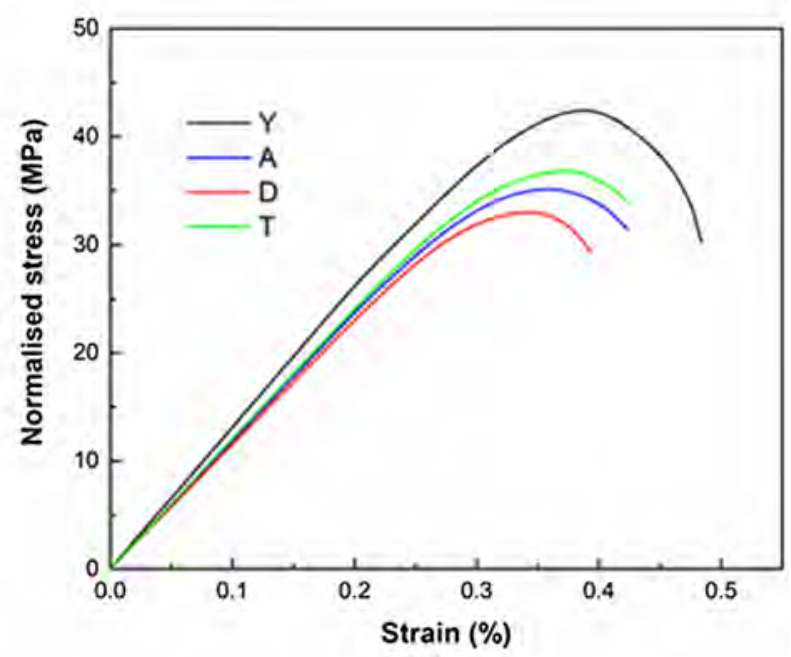

(c)

Fig. 8. Original (a), and normalised (accounting for solid fraction) for statistical realizations (b) and averaged (c) stress-strain curves of four groups prior to crack initiation (the end point of each curve corresponds to the complete failure of the first cohesive element).

cement lines and interstitial bone, particularly in the young group (Fig. 10). Compared with other groups, the diseased group had more cracks originating from Haversian canals than from the edges.

In relation to the driving force of crack propagation, the young group showed the highest peak as well as the largest subsequent force of all the groups. It was followed by the treated, aged and diseased groups (Fig. 11). The treated group was more resistant to crack growth in comparison to the aged and diseased groups, with a higher initial peak of the driving force at the beginning of the crack propagation process and at lower displacement. However, these differences were observed at a rather late stage of the crack propagation, where the crack driving force was already reduced to almost $1 / 3$ of its initial level. Further analysis was focused on the normalised uncracked ligaments. They were calculated as projection of the width of the uncracked tissue on the direction transversal to the applied load and divided by the total specimen's width. This was based on the fact that the tissue transversal to the loading direction bears most of the applied load. This analysis revealed that there was more undamaged tissue per unit width in the young and treated groups on average than in the aged and diseased groups (Fig. 12).

To further elucidate possible roles of microconstituents during crack propagation, the values of crack lengths, calculated as the total length of all fully damaged cohesive elements, which fall within respective microconstituents, were analysed and presented in Table 3. The results showed that the young group had the longest cracks as well as a significantly larger proportion of cracks in the CL-IB interface (14.94\%) - more than seven times higher than that of the aged group (2.12\%), which had the smallest amount of crack at this interface. The treated group presented the second-longest crack length as well as CL-IB interface cracks (9.39\%). Compared with the other two groups, the diseased and aged groups had relatively small total crack lengths and lower portions of CLIB interface cracks, while having the longest fractions of osteonal cracks $(51.64 \%$ in the diseased group) and interstitial cracks (55.26\% in the aged group). 


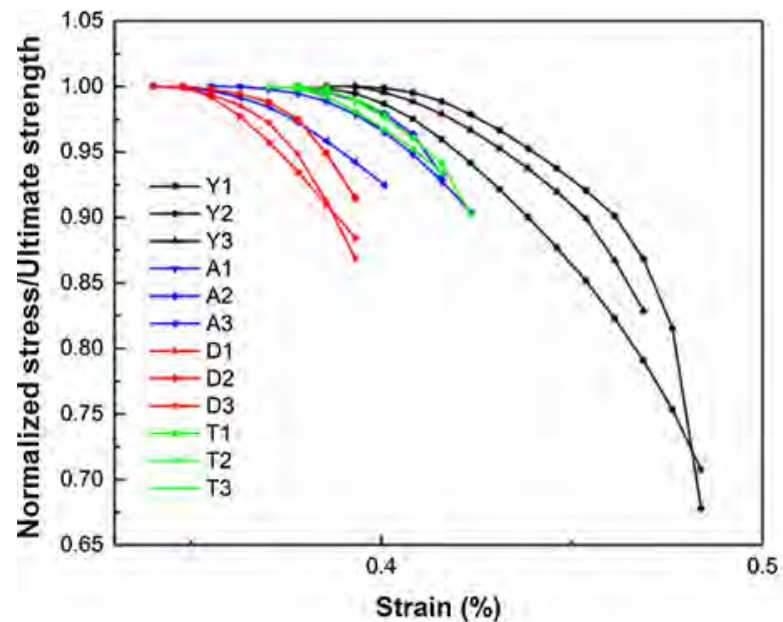

(a)

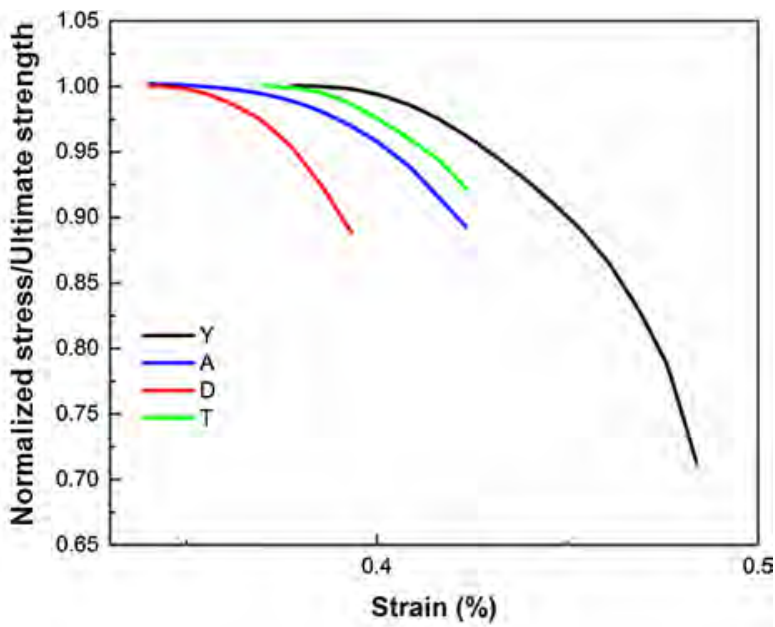

(b)

Fig. 9. Simulation results for stress nominalised with UTS for statistical realizations (a) and averaged curves (b) from ultimate strength to crack initiation (the end point of each curve corresponds to the complete failure of the first cohesive element).

Calculating the area under the force-displacement curves gave the energy necessary to complete fracture of the specimen. The highest work of fracture was found in the young group, with an average value of $0.322 \mathrm{~mJ}$, significantly higher - by $43.8 \%$ - than the average of the other three groups. The treated group had the second-largest work of fracture with 0.224 mJ, significantly higher than the diseased group $(0.154 \mathrm{~mJ})$ as shown in Fig. 13. Dividing the total energy with the total crack length of each specimen, revealed that there were two distinct tiers within the groups: the young and treated had a higher energy consumption per unit crack length $(0.136 \mathrm{~mJ} / \mathrm{mm}$ and $0.130 \mathrm{~mJ} / \mathrm{mm}$, respectively) compared with that of the aged and diseased groups $(0.115 \mathrm{~mJ} / \mathrm{mm}$ and $0.118 \mathrm{~mJ} / \mathrm{mm}$, respectively).

\subsection{Discussion}

In this study, four-phase microstructured cortical bone models with zero-thickness cohesive elements were developed to evaluate the effects of micro-morphology in four groups of patients on crack initiation and propagation. Results from the micro-morphological analysis revealed that both areal fractions and microconstituent parameters were different among the studied groups. A reduced osteonal bone fraction and increased porosity were most prominent in the aged and disease groups; both were accompanied by higher Haversian radii and a reduction in the area of individual osteons, confirming results of previous studies [2,29]. Although there was no significant difference in terms of the aspect ratio of osteons among the groups, thus maintaining their morphological character, a larger Haversian radius within the same osteonal area reduced thickness of the osteonal tissue. The last is known to be linked with poor osteonal geometric indices, resulting in weakened mechanical performance [2]. Bisphosphonate treatment disrupts bone turnover by partially inhibiting the function of osteoclasts [38] and demonstrated in our study a clear improvement in terms of the reduction of the Haversian radius compared with the aged and diseased groups.

Changes in bone quality and its morphological parameters were long believed to contribute towards the variation of mechanical properties of cortical bone. There are many arguments from both sides either emphasizing or cross-validating possible roles of fracture toughening and/or softening mechanisms [28,31-36]. However, it is often difficult to assess a single effect due to the multifactorial nature of performance and fracture of bone tissue and strong interaction between various mechanisms. The developed model provided a unique way of evaluating the role of micro-morphology independently of bone quality - local material heterogeneity due to variation in bone mineral density. The predicted mechanical properties differed significantly among the groups, but were in the same range with the previous experimental data [36]. Benefiting from the low porosity and the large osteonal areal fraction, the young group exceeded the mechanical performance of the others by a large margin, with values higher by $23.6 \%, 35.9 \%$ and $8.8 \%$ than the average values for the tissue modulus, UTS and failure strain, respectively, for the other three groups. The treated group outperformed the diseased group in terms of both elastic and post-UTS regions, thanks to the reduced size of Haversian canals and a slightly larger individual osteonal area, confirming findings from the previous study [2]. This advantage in the elastic region was diminished when the contribution from porosity was accounted for, suggesting that the effect of treatment with bisphosphonate resulted mostly from the reduction of canal porosity, potentially caused by inhibiting the normal function of osteoclasts [38]. A gap in performance between the young group and the other three groups was clearly visible at any given displacement, indicating a better fracture resistance capacity of this group. (Fig. 11).

These results suggest that the osteonal morphology, in addition to local variations in the mineral content, could indeed affect the crack propagation path, which in turn, influences the tissue-level mechanical behaviour of cortical bone. These results suggest that the crack propagation process was greatly influenced by the distribution and areal fractions of microconstituents. More crack deflections into cement lines seems to associate to higher crack retention, while more cracks in osteons or interstitial matrix might be linked to the lower crack retention as a result.

Initiation and evolution of damage in bones of various groups were affected by the respective porosity and areal factions of 


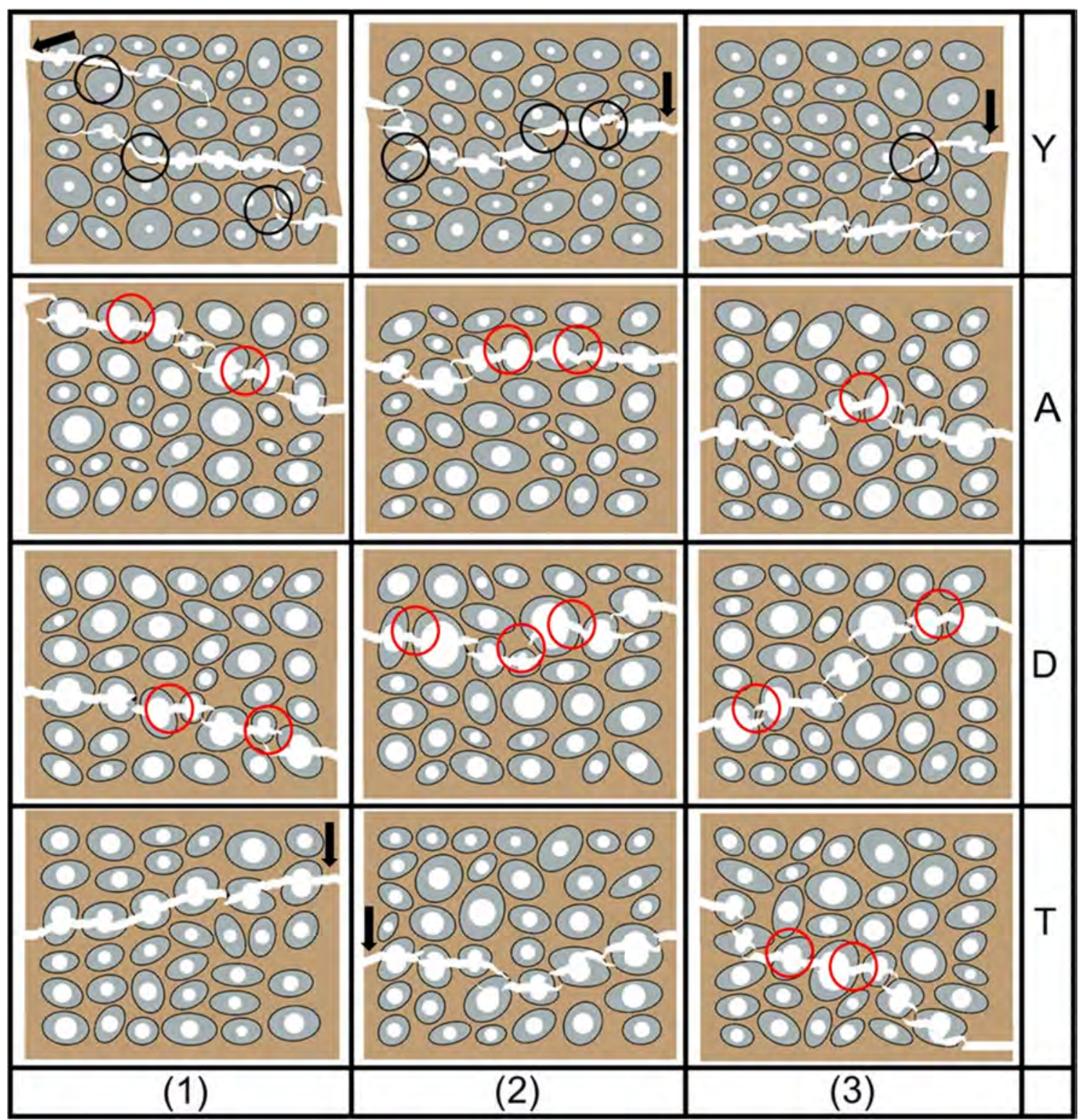

Fig. 10. Crack propagation in four groups (three statistical realization of micro-morphology for each group). The black arrows indicate the crack initiation at free edges of the sample, the red circles indicate multiple cracks initiation at large Haversian canals prior to failure and the black circles indicate the crack growth along cement lines in the young group.

microconstituents. The initiation of cracks at Haversian canals might have promoted an early degradation process in both aged and diseased groups due to the presence of larger adjacent Haversian canals. Whereas in the young and treated group a delayed initiation process was observed, with initiations of cracks appearing at the free edge or in smaller Haversian canals with greater distance from each other. Therefore, it is likely that the initiation was predominantly affected by the qualitative (morphological) character of the osteons and Haversian canals, such as the distribution of their diameters, rather than a quantitative factor such as areal fraction of porosity. In contrast, the evolution of damage was largely dominated by the osteonal areal fraction due to its intrinsically large strain-energy release rate. The higher osteonal areal fraction in the young group enhanced its load-bearing capacity to exceed strains of $0.47 \%$. And the fracture energy per unit crack length decreased from $0.136 \mathrm{~mJ} / \mathrm{mm}$ for the young group by $18.3 \%$ and $15.3 \%$, respectively, due to aging and osteoporosis, while the treated group had an average improvement of $10.2 \%$ compared with the diseased group.

The microstructured models with randomly distributed constituents enabled microscale evaluation of theoretical crack morphologies for each group. Distinct features of crack initiation and propagation paths were observed: larger Haversian radii and reduction in individual osteons prompted early crack initiation and propagation through Haversian canals causing lower fracture resistance in the aged and diseased groups. In contrast, relatively 'thick' osteons (as a result of smaller Haversian canals and larger areas of individual osteons) in the young group (and, to some extent, the treated one) led to crack deflection and arrest at the interface between cement lines and 


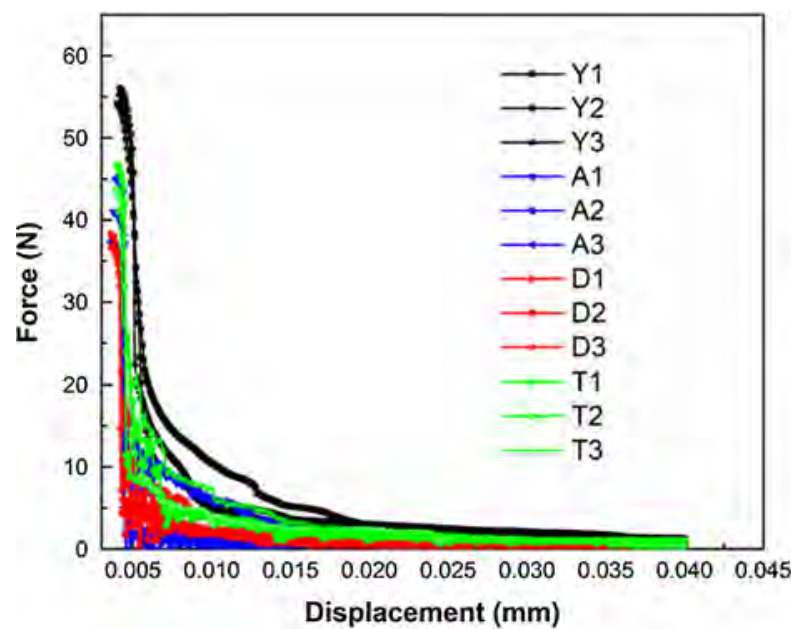

(a)

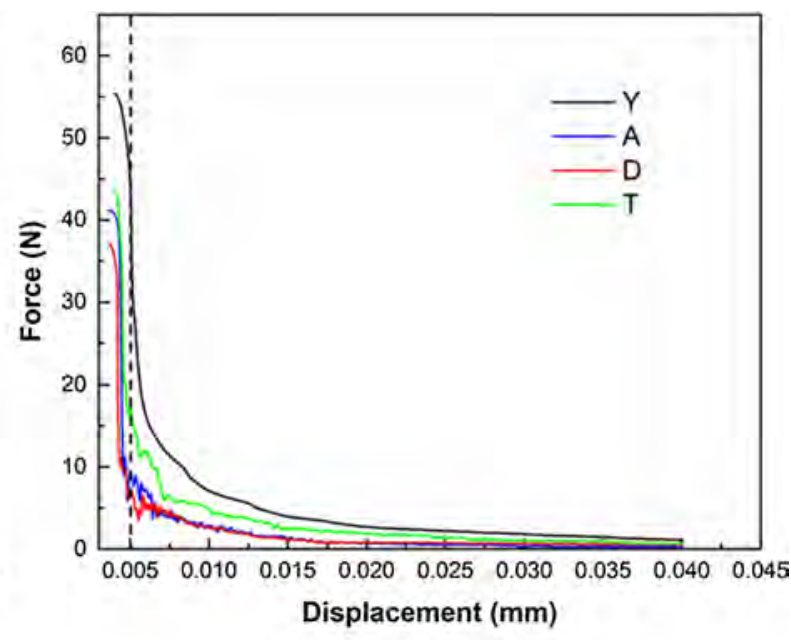

(b)

Fig. 11. Post-UTS force-displacement curves (the dashed line corresponds to the point when the crack driving force of the treated group outperformed that of the aged and diseased groups).

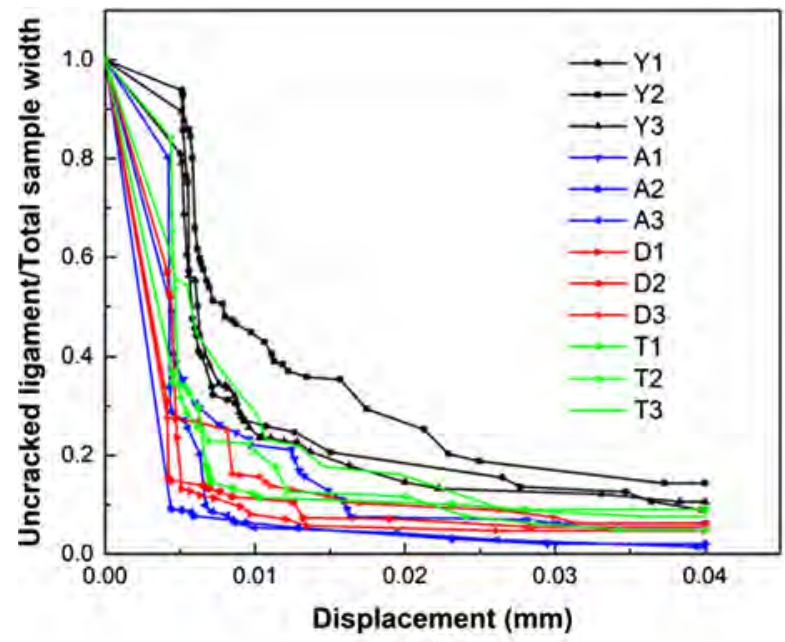

(a)

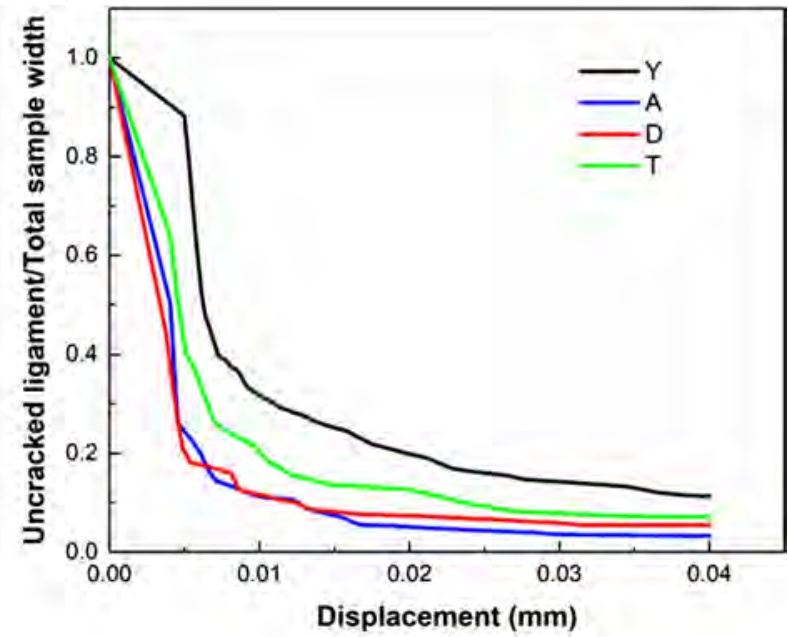

(b)

Fig. 12. Analysis of relationship between uncracked ligament (normalised with total sample width) during loading: (a) simulation results (b) averaged curves.

Table 3

Calculation results for total crack length and fraction of cracks in CL-IB interface and osteons for all statistical realisations of human cortical bone models (means and standard deviations, standard deviations resulting in negative values were replaced by maximum and minimum values).

\begin{tabular}{|c|c|c|c|c|c|}
\hline & $\begin{array}{l}\text { CL-IB interface crack length } \\
(\mathrm{mm})\end{array}$ & $\begin{array}{l}\text { Osteon crack length } \\
(\mathrm{mm})\end{array}$ & $\begin{array}{l}\text { Total crack length } \\
(\mathrm{mm})\end{array}$ & $\begin{array}{l}\text { CL-IB interface crack } \\
(\%)\end{array}$ & $\begin{array}{l}\text { Osteon crack } \\
(\%)\end{array}$ \\
\hline Young & $\begin{array}{l}0.366 \\
( \pm 0.236)\end{array}$ & $\begin{array}{l}1.106 \\
( \pm 0.119)\end{array}$ & $\begin{array}{l}2.374 \\
( \pm 0.341)\end{array}$ & $\begin{array}{l}14.94 \\
( \pm 7.51)\end{array}$ & $\begin{array}{l}47.86 \\
( \pm 8.93)\end{array}$ \\
\hline Aged & $\begin{array}{l}0.027 \\
(\min 0.001 \\
\max 0.060)\end{array}$ & $\begin{array}{l}0.608 \\
( \pm 0.131)\end{array}$ & $\begin{array}{l}1.442 \\
( \pm 0.222)\end{array}$ & $\begin{array}{l}2.12 \\
(\min 0.04 \\
\max 4.96)\end{array}$ & $\begin{array}{l}42.62 \\
( \pm 9.35)\end{array}$ \\
\hline Diseased & $\begin{array}{l}0.016 \\
( \pm 0.015)\end{array}$ & $\begin{array}{l}0.670 \\
( \pm 0.092)\end{array}$ & $\begin{array}{l}1.294 \\
( \pm 0.062)\end{array}$ & $\begin{array}{l}2.32 \\
(\min 0 \\
\max 5.50)\end{array}$ & $\begin{array}{l}51.64 \\
( \pm 5.52)\end{array}$ \\
\hline Treated & $\begin{array}{l}0.112 \\
( \pm 0.084)\end{array}$ & $\begin{array}{l}0.765 \\
( \pm 0.100)\end{array}$ & $\begin{array}{l}1.722 \\
( \pm 0.072)\end{array}$ & $\begin{array}{l}9.39 \\
( \pm 2.99)\end{array}$ & $\begin{array}{l}44.38 \\
( \pm 4.79)\end{array}$ \\
\hline
\end{tabular}




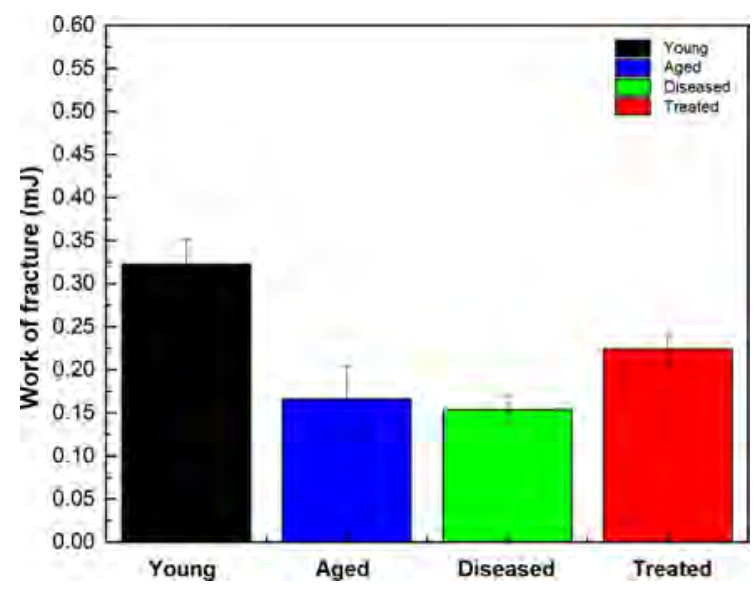

Fig. 13. Work of fracture of four groups of human cortical bone.

interstitial bone. Additional quantitative assessment of crack morphologies suggested that the enhanced fracture resistance manifested in the young and treated groups resulted from a higher necessary crack driving force to allow crack propagation. This finding was also supported by a larger proportion of uncracked ligament bridging, which, in turn, was caused by crack deflection and/or arrest at interfaces of cement lines and interstitial bone (Fig. 10). These extrinsically corroborated toughening mechanisms are understood to improve collectively the fracture resistance of cortical bone [6,37-39]. Realisation of these two mechanisms meant that the adjacent osteons were prevented from complete perforation by cracks, and their paths had to reach a greater length before crack coalescence. Previous studies also suggested that cement lines acted as a weak interface and sacrificial barrier to prevent crack propagating through osteons [38-50]. In addition, the larger areal fraction of osteons increased not only the proportion of high-toughness constituents (e.g. osteons in comparison with interstitial matrix, CL-IB interface and Haversian canals), but also the fraction of the CL-IB interface, promoting crack propagating within the CL-IB interface significantly. In our study, both the young and treated groups had a significantly larger chance of crack propagation in CL-IB interface compared with the aged and diseased groups.

When discussing the influence of the CL-IB interface, it is important to note that most current models did not directly model cement lines as a result of inconclusive understanding of their properties. Some earlier studies described a cement line as a weak interface, mineraldeficient and viscous in its nature [28,51]. More recent studies, however, provided rather contradicting results, where cement lines were found as hypermineralized in studies performed with qualitative backscattered electron imaging (qBEI), quantitative energy dispersive Xray spectroscopy (qEDX) and micro-Raman spectroscopy ( $\mu$-Raman) $[9,29]$. It is, therefore, understandable to assume that cement lines have a higher elastic module, if to consider a positive correlation between its local magnitude and a bone mineral content. Still, results obtained with nanoindentation measurements presented another interesting twist, whereby direct mechanical testing showed that the cement line had some $30 \%$ lower levels of the elastic modulus and hardness of the surrounding tissue [30,52]. Further investigation at lamellar level revealed a periodic alternation of stiffness between lamellar layers [32,53,54], suggesting a probable existence of weak interfaces in a transition zone between lamellae rather than at the demarcation of the cement line [31,32]. Previous modelling works showed that equal or stiffer cement line might (but not necessarily) promote the crack arrest at a cement line [18,22]. Indeed, introduction of a higher elastic modulus to the CL-IB interface in one young and one aged numerical models as a case study (Appendix A) resulted in a decreasing proportion of cracks observed in the CL-IB interface, in line with other modelling works [18,22]. This contrasts with widely accepted experimental observations - cracks propagating along cement lines. So, in future studies, it would be worthwhile to consider the sub-micro level of alternating lamellar layers and assess performance of a hypermineralized cement line to gain a fuller picture of the structural-function relationship of the osteonal system and its effect on crack propagation in a cortical bone tissue.

Interestingly, although increasing the fraction of osteonal area would be a sensible way to promote fracture resistance, it seemed that a slightly larger osteonal area fraction in the diseased group did not provide any advantage over the aged group. On the contrary, larger Haversian canals and a smaller distance between the adjacent canals promoted crack initiation and propagation in the diseased group. Therefore, when evaluating multiple competing factors responsible for fracture resistance, our study showed that the osteonal morphology has a stronger impact than its areal fraction.

\section{Conclusions}

In summary, the developed microstructured models employing zero-thickness cohesive elements allowed elucidation of the effect of micro-morphology on crack initiation and propagation in samples of human cortical bone derived from four groups of patients. Multiple crack initiation, propagation and branching were observed and assessed for the studied groups, with distinct crack propagation paths and supporting fracture toughening mechanisms. Morphological variations stemming from specific features of spatial distributions, areal fractions and local parameters of microconstituents were measured and their effect on bone fracture performance analysed. It was shown that both the qualitative and quantitative features of microconstituents effectively altered the mechanical properties of human cortical bone. It was found that fracture toughening mechanisms such as cement-line deflection and uncracked ligament bridging were more sensitive to the changes in quality of local microconstituents than their quantity. The developed 
computational model provided new ways to analyse structure-function relationships of cortical bone in silico, which could provide additional support for understanding and developing new therapeutic interventions aimed at reduction of the risks of bone fractures.

\section{Declaration of Competing Interest}

The authors declared that there is no conflict of interest.

\section{Acknowledgements}

MQ is a fellow of the Alexander von Humboldt Foundation. BB is supported by a grant from the German Research Foundation (DFG) (BU 2562/3-1).

\section{Authors' roles}

Study design: SL, MW, VVS. Data analysis: MW. Data interpretation: SL, MW, AVS, MQ, BB and VVS. Drafting manuscript: MW, SL. Revising manuscript content: SL, MW, AVS, MQ, BB and VVS. Approving final version of manuscript: all authors.

\section{Appendix A}

In addition to the main study, a case study was also conducted to investigate the effect of high-modulus cement lines on crack propagation for one young and one aged model and to provide a foundation for discussion on recent suggestions in this area. The two models were kept the same as in the main study, apart from the value of the CL-IB interface's modulus, which was assumed 11\% higher based on the difference between the mean calcium content of cement lines and osteons reported in [9].

This case study with a stiffer CL-IB interface revealed that its higher modulus resulted in a reduction of crack deflection in these regions (Fig. A1). For both the young and the aged cases, the original models (with the CL-IB interface's modulus lower by $25 \%$ than that of the osteons) resulted in crack deflections around the cement line-interstitial bone interface; while for high-modulus CL-IB

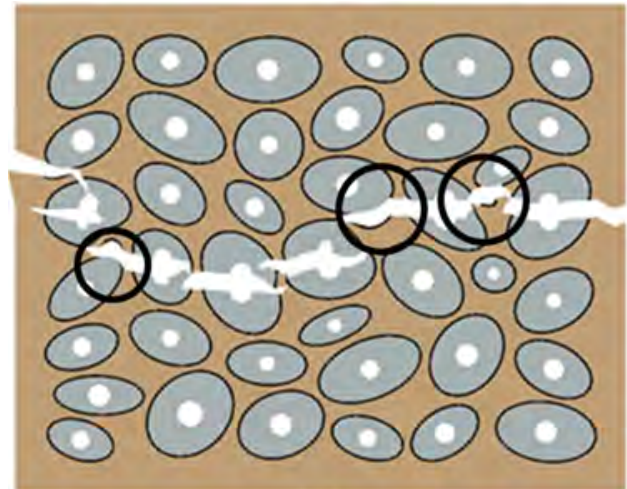

(a)

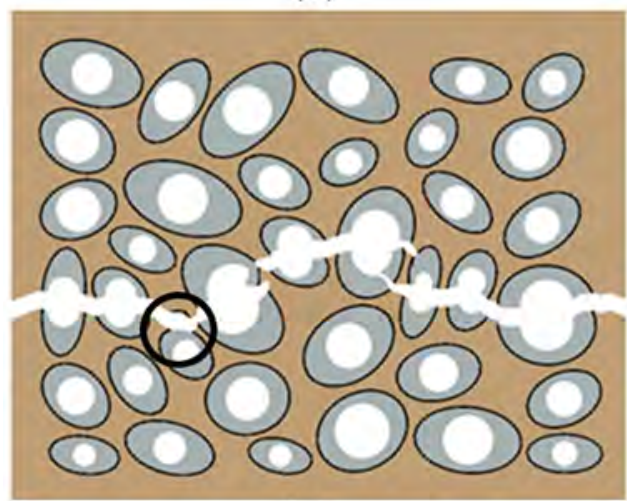

(c)

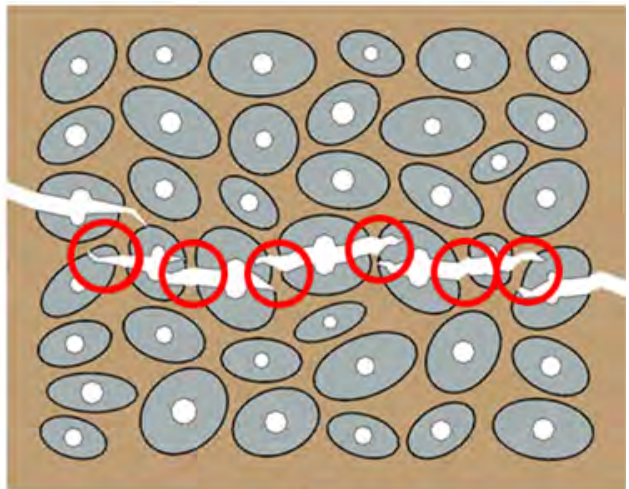

(b)

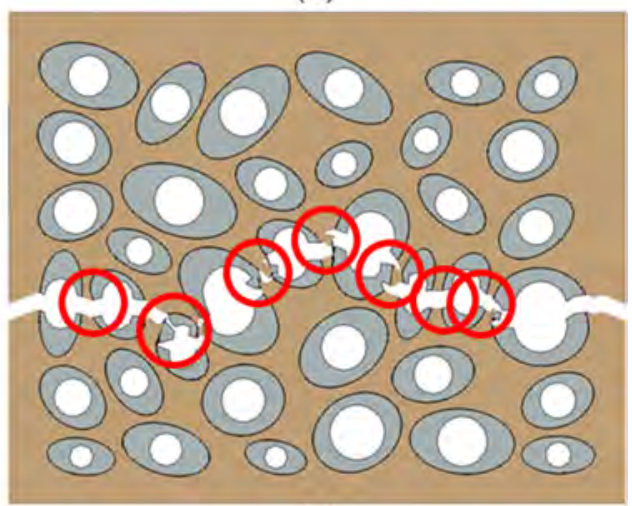

(d)

Fig. A1. Analysis of effect of high-modulus cement line-interstitial bone interfaces in cortical bones for young (a and b) and aged (c and d) groups. In original simulations ( $a$ and c), the elastic modulus of the CL-IB interface was considered $25 \%$ lower than that of the osteons, while in the case of the high-modulus CL-IB interface (b and d) it was $11 \%$ higher [9]. Black circles indicate the crack propagation in the CL-IB interface, while red circles denote crack penetration through the osteons. 
interfaces the crack propagated into the adjacent osteons instead. The results with a high-modulus CL-IB interface contrast with widely accepted experimental observations, where cracks were found propagating along cement lines. The outcome of this case study could suggest that the high-modulus cement lines may not be the only source of weaknesses during processes of crack initiation and propagation. The changing mismatch of material properties at the interface, e.g. due to alternating high and low levels of interlamellar modulus as an example of material heterogeneity [55], may also contribute to this.

\section{References}

[1] British Orthopaedic Association, The care of patients with fragility fracture, London, 2007.

[2] Bernhard A, Milovanovic P, Zimmermann EA, Hahn M, Djonic D, Krause M, et al. Micro-morphological properties of osteons reveal changes in cortical bone stability during aging, osteoporosis, and bisphosphonate treatment in women. Osteoporos Int 2013;24:2671-80. https://doi.org/10.1007/s00198-013-2374-x.

[3] Zimmermann EA, Busse B, Ritchie RO. The fracture mechanics of human bone: influence of disease and treatment. Bonekey Rep 2015;4:743. https://doi.org/10. 1038/bonekey.2015.112.

[4] Rolvien T, Stürznickel J, Schmidt FN, Butscheidt S, Schmidt T, Busse B, et al. Comparison of bone microarchitecture between adult osteogenesis imperfecta and early-onset osteoporosis. Calcif Tissue Int 2018;103:512-21. https://doi.org/10.1007/s00223-018-0447-8.

[5] Granke M, Makowski AJ, Uppuganti S, Nyman JS. Prevalent role of porosity and osteonal area over mineralization heterogeneity in the fracture toughness of human cortical bone. J Biomech 2016;49:2748-55. https://doi.org/10.1016/J.JBIOMECH.2016.06.009.

[6] Rho J-Y, Kuhn-Spearing L, Zioupos P. Mechanical properties and the hierarchical structure of bone. Med Engng Phys 1998;20:92-102. https://doi.org/10.1016/ S1350-4533(98)00007-1.

[7] Ritchie RO, Kinney JH, Kruzic JJ, Nalla RK. A fracture mechanics and mechanistic approach to the failure of cortical bone. Fatigue Fract Engng Mater Struct 2005;28:345-71. https://doi.org/10.1111/j.1460-2695.2005.00878.x.

[8] Cowin SC, Hegedus DH. Bone remodeling I: Theory of adaptive elasticity. J Elast 1976. https://doi.org/10.1007/BF00041724.

[9] Milovanovic P, vom Scheidt A, Mletzko K, Sarau G, Püschel K, Djuric M, et al. Bone tissue aging affects mineralization of cement lines. Bone 2018. https://doi. org/10.1016/j.bone.2018.02.004.

[10] Mulhern DM. Rib remodeling dynamics in a skeletal population from Kulubnarti, Nubia. Am J Phys Anthropol 2000;111:519-30. https://doi.org/10.1002/(SICI) 1096-8644(200004)111:4<519::AID-AJPA7 > 3.0.CO;2-7.

[11] Bell KL, Loveridge N, Reeve J, Thomas CDL, Feik SA, Clement JG. Super-osteons (remodeling clusters) in the cortex of the femoral shaft: Influence of age and gender. Anat Rec 2001;264:378-86. https://doi.org/10.1002/ar.10014.

[12] Rho JY, Zioupos P, Currey JD, Pharr GM. Microstructural elasticity and regional heterogeneity in human femoral bone of various ages examined by nanoindentation. J Biomech 2002;35:189-98. https://doi.org/10.1016/S0021-9290(01)00199-3.

[13] Yoshino M, Imaizumi K, Miyasaka S, Seta S. Histological estimation of age at death using microradiographs of humeral compact bone. Forensic Sci Int 1994;64:191-8. https://doi.org/10.1016/0379-0738(94)90231-3.

[14] Budyn É, Hoc T. Analysis of micro fracture in human Haversian cortical bone under transverse tension using extended physical imaging. Int J Numer Meth Engng 2009;82:940-65. https://doi.org/10.1002/nme.2791.

[15] Yang QD, Cox BN, Nalla RK, Ritchie RO. Fracture length scales in human cortical bone: the necessity of nonlinear fracture models. Biomaterials 2006;27:2095-113. https://doi.org/10.1016/J.BIOMATERIALS.2005.09.040.

[16] Ural A, Vashishth D. Cohesive finite element modeling of age-related toughness loss in human cortical bone. J Biomech 2006;39:2974-82. https://doi.org/10. 1016/J.JBIOMECH.2005.10.018.

[17] Pereira FAM, Morais JJL, de Moura MFSF, Dourado N, Dias MIR. Evaluation of bone cohesive laws using an inverse method applied to the DCB test. Engng Fract Mech 2012;96:724-36. https://doi.org/10.1016/J.ENGFRACMECH.2012.10.002.

[18] Ural A, Mischinski S. Multiscale modeling of bone fracture using cohesive finite elements. Engng Fract Mech 2013;103:141-52. https://doi.org/10.1016/J. ENGFRACMECH.2012.05.008.

[19] Mischinski S, Ural A. Finite element modeling of microcrack growth in cortical bone. J Appl Mech 2011;78:041016https://doi.org/10.1115/1.4003754.

[20] Budyn É, Hoc T. Multiple scale modeling for cortical bone fracture in tension using X-FEM. Eur J Comput Mech 2007;16:213-36. https://doi.org/10.3166/remn. 16.213-236.

[21] Abdel-Wahab AA, Maligno AR, Silberschmidt VV. Micro-scale modelling of bovine cortical bone fracture: Analysis of crack propagation and microstructure using X-FEM. Comput Mater Sci 2012;52:128-35. https://doi.org/10.1016/J.COMMATSCI.2011.01.021.

[22] Li S, Abdel-Wahab A, Demirci E, Silberschmidt VV. Fracture process in cortical bone: X-FEM analysis of microstructured models. Int J Fract 2013;184. https:// doi.org/10.1007/s10704-013-9814-7.

[23] Idkaidek A, Jasiuk I. Cortical bone fracture analysis using XFEM - case study. Int J Numer Method Biomed Eng 2017;33:e2809https://doi.org/10.1002/cnm. 2809.

[24] Ural A, Zioupos P, Buchanan D, Vashishth D. The effect of strain rate on fracture toughness of human cortical bone: a finite element study. J Mech Behav Biomed Mater 2011;4:1021-32. https://doi.org/10.1016/J.JMBBM.2011.03.011.

[25] Budyn E, Hoc T, Jonvaux J. Fracture strength assessment and aging signs detection in human cortical bone using an X-FEM multiple scale approach. Comput Mech 2008;42:579-91. https://doi.org/10.1007/s00466-008-0283-1.

[26] Su XT, Yang ZJ, Liu GH. Monte Carlo simulation of complex cohesive fracture in random heterogeneous quasi-brittle materials: a 3D study. Int J Solids Struct 2010;47:2336-45. https://doi.org/10.1016/J.IJSOLSTR.2010.04.031.

[27] Grynpas M. Age and disease-related changes in the mineral of bone. Calcif Tissue Int 1993;53. https://doi.org/10.1007/BF01673403.

[28] Burr D, Schaffler M, Frederickson RG. Composition of the cement line and its possible mechanical role as a local interface in human compact bone. J Biomech 1988;21. https://doi.org/10.1016/0021-9290(88)90132-7.

[29] Skedros John G, Holmes Jennifer L, Vajda Eric G, Bloebaum Roy D. Cement lines of secondary osteons in human bone are not mineral-deficient: new data in a historical perspective. Anat Rec 2005;286A(1):781-803. https://doi.org/10.1002/(ISSN)1552-489210.1002/ar.a.v286a:110.1002/ar.a.20214.

[30] Montalbano T, Feng G. Nanoindentation characterization of the cement lines in ovine and bovine femurs. J Mater Res 2011;26:1036-41. https://doi.org/10. 1557/jmr.2011.46.

[31] Bigley RF, Griffin LV, Christensen L, Vandenbosch R. Osteon interfacial strength and histomorphometry of equine cortical bone. J Biomech 2006;39:1629-40. https://doi.org/10.1016/j.jbiomech.2005.05.006.

[32] Katsamenis OL, Chong HMH, Andriotis OG, Thurner PJ. Load-bearing in cortical bone microstructure: selective stiffening and heterogeneous strain distribution at the lamellar level. J Mech Behav Biomed Mater 2013;17:152-65. https://doi.org/10.1016/j.jmbbm.2012.08.016.

[33] Bayraktar HH, Morgan EF, Niebur GL, Morris GE, Wong EK, Keaveny TM. Comparison of the elastic and yield properties of human femoral trabecular and cortical bone tissue. J Biomech 2004;37:27-35. https://doi.org/10.1016/S0021-9290(03)00257-4.

[34] Li S, Demirci E, Silberschmidt VV. Variability and anisotropy of mechanical behavior of cortical bone in tension and compression. J Mech Behav Biomed Mater 2013;21:109-20. https://doi.org/10.1016/j.jmbbm.2013.02.021.

[35] Mohsin S, O’Brien FJ, Lee TC. Osteonal crack barriers in ovine compact bone. J Anat 2006;208:81-9. https://doi.org/10.1111/j.1469-7580.2006.00509.x.

[36] Reilly DT, Burstein AH. The elastic and ultiamate properties of compact bone tissue. J Biomech 1975;8:393-405. https://doi.org/10.1016/0021-9290(75) 90075-5. 
[37] Wachter N, Krischak G, Mentzel M, Sarkar M, Ebinger T, Kinzl L, et al. Correlation of bone mineral density with strength and microstructural parameters of cortical bone in vitro. Bone 2002;31:90-5. https://doi.org/10.1016/S8756-3282(02)00779-2.

[38] Cramer JA, Gold DT, Silverman SL, Lewiecki EM. A systematic review of persistence and compliance with bisphosphonates for osteoporosis. Osteoporos Int 2007;18:1023-31. https://doi.org/10.1007/s00198-006-0322-8.

[39] Granke M, Grimal Q, Saïed A, Nauleau P, Peyrin F, Laugier P. Change in porosity is the major determinant of the variation of cortical bone elasticity at the millimeter scale in aged women. Bone 2011;49:1020-6. https://doi.org/10.1016/J.BONE.2011.08.002.

[40] Neil Dong X, Edward Guo X. The dependence of transversely isotropic elasticity of human femoral cortical bone on porosity. J Biomech 2004;37:1281-7. https:// doi.org/10.1016/J.JBIOMECH.2003.12.011.

[41] Currey JD. Effects of differences in mineralization on the mechanical properties of bone. Philos Trans R Soc B Biol Sci 1984;304:509-18. https://doi.org/10. 1098/rstb.1984.0042.

[42] Zioupos PP, Currey JD. Changes in the stiffness, strength, and toughness of human cortical bone with age. Bone 1998;22:57-66. https://doi.org/10.1016/S87563282(97)00228-7.

[43] Seeman E, Delmas PD. Bone quality — The material and structural basis of bone strength and fragility. N Engl J Med 2006;354:2250-61. https://doi.org/10. 1056/NEJMra053077.

[44] Augat P, Schorlemmer S. The role of cortical bone and its microstructure in bone strength. Age Ageing 2006;35. https://doi.org/10.1093/ageing/afl081. ii27-ii31.

[45] Nalla RK, Stölken JS, Kinney JH, Ritchie RO. Fracture in human cortical bone: local fracture criteria and toughening mechanisms. J Biomech 2005;38:1517-25. https://doi.org/10.1016/J.JBIOMECH.2004.07.010.

[46] Launey ME, Buehler MJ, Ritchie RO. On the mechanistic origins of toughness in bone 2010. https://doi.org/10.1146/annurev-matsci-070909-104427.

[47] Nalla RK, Kruzic JJ, Kinney JH, Ritchie RO. Effect of aging on the toughness of human cortical bone: evaluation by R-curves. Bone 2004;35:1240-6. https://doi. org/10.1016/j.bone.2004.07.016.

[48] O'Brien FJ, Taylor D, Lee TC. The effect of bone microstructure on the initiation and growth of microcracks. J Orthop Res 2005;23:475-80. https://doi.org/10. 1016/j.orthres.2004.08.005.

[49] Chan KS, Chan CK, Nicolella DP. Relating crack-tip deformation to mineralization and fracture resistance in human femur cortical bone. Bone 2009;45:427-34. https://doi.org/10.1016/J.BONE.2009.01.468.

[50] Chan KS, Lee Y-D, Nicolella DP, Furman BR, Wellinghoff S, Rawls R. Improving fracture toughness of dental nanocomposites by interface engineering and micromechanics. Engng Fract Mech 2007;74:1857-71. https://doi.org/10.1016/J.ENGFRACMECH.2006.07.013.

[51] Schaffler MB, Burr DB, Frederickson RG. Morphology of the osteonal cement line in human bone. Anat Rec 1987;217:223-8. https://doi.org/10.1002/ar. 1092170302.

[52] Conward M, Samuel J. Machining characteristics of the haversian and plexiform components of bovine cortical bone. J Mech Behav Biomed Mater 2016;60:525-34. https://doi.org/10.1016/j.jmbbm.2016.03.017.

[53] Gupta HS, Stachewicz U, Wagermaier W, Roschger P, Wagner HD, Fratzl P. Mechanical modulation at the lamellar level in osteonal bone 2019. https://doi.org/ 10.1557/JMR.2006.0234.

[54] Faingold A, Cohen SR, Wagner HD. Nanoindentation of osteonal bone lamellae. J Mech Behav Biomed Mater 2012;9:198-206. https://doi.org/10.1016/j. jmbbm.2012.01.014.

[55] Katsamenis OL, Jenkins T, Thurner PJ. Toughness and damage susceptibility in human cortical bone is proportional to mechanical inhomogeneity at the osteonal-level. Bone 2015;76:158-68. https://doi.org/10.1016/j.bone.2015.03.020. 